\title{
Comunicação
}

[Communication]

\section{Síndrome de Sézary em cadela}

\author{
[Sézary syndrome in a bitch] \\ S.M. Rodigheri ${ }^{1}$, M.R. Farias $^{2 *}$ J. Werner $^{3}$, T.R. Macedo ${ }^{1}$, M.A.B. Ostrowski ${ }^{1}$ \\ ${ }^{1}$ Medico veterinário residente - PUC-PR \\ ${ }^{2}$ Pontificia Universidade Católica \\ BR $376-\mathrm{km} 14$ \\ 80010-500 - São José dos Pinhais, PR \\ ${ }^{3}$ Médica veterinária autônoma
}

O linfoma cutâneo é uma neoplasia linfóide maligna que representa de 3 a $8 \%$ das neoplasias tegumentares em cães. Geralmente acomete cães idosos, principalmente das raças Cocker Spaniel, Bulldog Inglês, Boxer e Golden Retrievers. Pode ser classificado em: não-epiteliotrópico, originário de linfócitos $\mathrm{B}$ ou epiteliotrópico, originário de linfócitos T (Morrison, 1998).

O linfoma cutâneo epiteliotrópico manifesta-se sob três formas distintas: micose fungóide, síndrome de Sézary e reticulose pagetóide (Morrison, 1998). A síndrome de Sézary foi descrita em 1938 como uma variante leucêmica da micose fungóide (Anadolu et al., 2005), sendo caracterizada por eritrodermia generalizada, prurido intenso, linfadenomegalia e leucemia, podendo estar associada à presença de nódulos e placas tegumentares (Foster, 1997).

O objetivo deste trabalho é relatar um caso de síndrome de Sézary em uma cadela, discorrendo sobre seus principais aspectos clínicos, diagnósticos, terapêuticos e prognósticos.

Uma cadela da raça Cocker Spaniel, com cinco anos de idade, foi atendida em hospital veterinário, com histórico de múltiplas lesões alopécicas, eritematoescamativas e nodulares com evolução de três meses. Ao exame clínico foi constatada linfadenomegalia submandibular e poplítea e a presença de múltiplas placas e nódulos coalescentes, epidermodermais, firmes, violáceos distribuídos pela face, tronco e membros (Fig.1).

A citologia aspirativa de linfonodos e lesões tegumentares revelou a presença de inúmeros linfoblastos. A avaliação histológica demonstrou infiltração severa da derme por linfócitos jovens que exibiam anisocariose, atipia nuclear e índice mitótico elevado (Fig. 2), os quais convergiam e proliferavam pela epiderme formando coleções de linfócitos neoplásicos denominadas microabscessos de Pautrier (Fig. 3). A análise imunoistoquímica foi positiva para o anticorpo anti-CD3, o que subsidiou o diagnóstico de linfoma cutâneo epiteliotrópico.

A paciente foi tratada com poliquimioterapia sistêmica baseada no protocolo de MadisonWisconsin (L-VCA-Short) e antibioticoterapia. A resposta ao tratamento quimioterápico foi desfavorável, ocorrendo progressão e disseminação das lesões tegumentares, as quais tenderam a ulceração e crostificação e foram associadas a prurido intenso, apatia, anorexia, febre e emaciação.

Recebido em 24 de maio de 2007

Aceito em 21 de setembro de 2007

*Autor para correspondência (corresponding author)

E-mail: marconi.farias@pucpr.br 


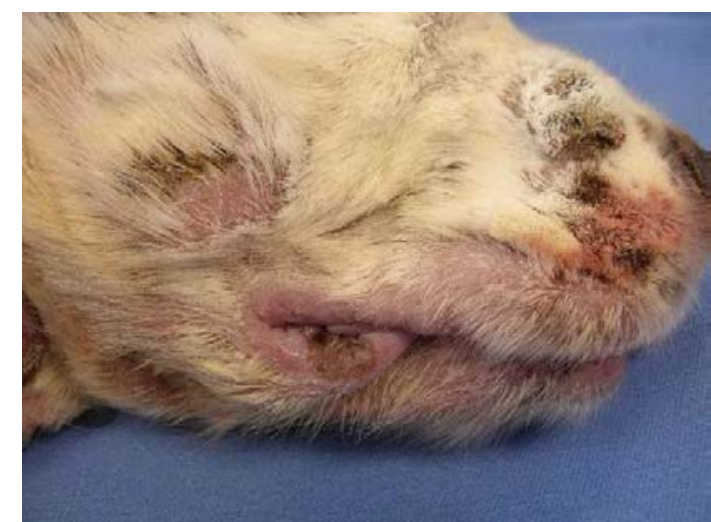

A

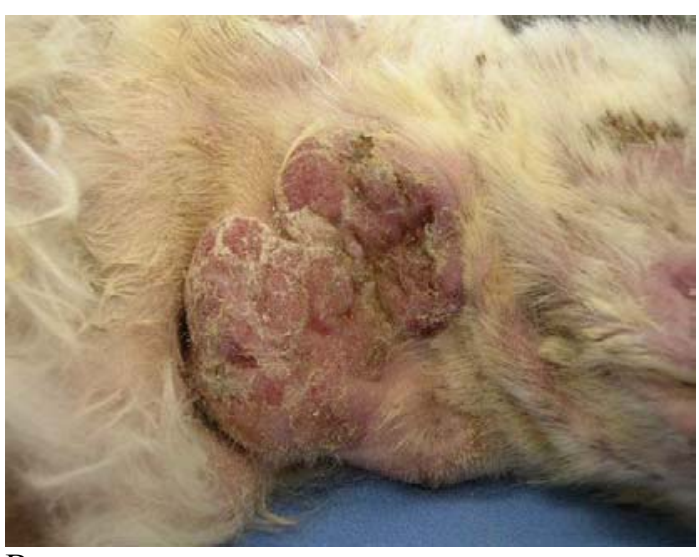

B

Figura 1. Cadela com síndrome de Sézary. A) Lesão alopécica, eritematosa, úlcerocrostosa e nodular na face; B) Lesão nodular, úlcerocrostosa na região cervical; C) Nódulo alopécico, eritemoescamativo (membros torácicos e pélvicos); D) Lesão tegumentar nodular e úlcerocrostosa.

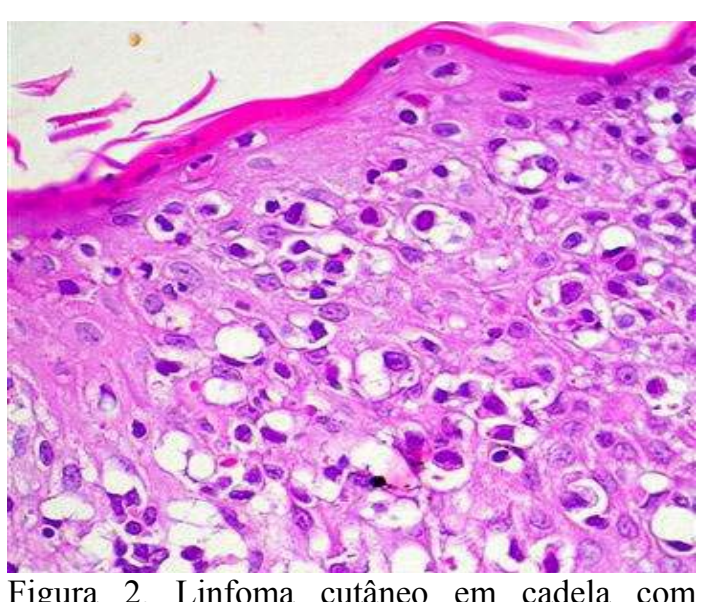

Figura 2. Linfoma cutâneo em cadela com

síndrome de Sézary. HE. 400x.

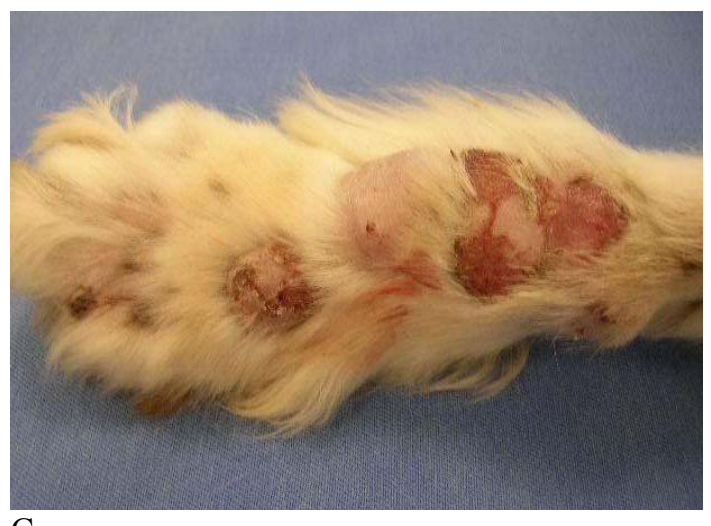

$\mathrm{C}$

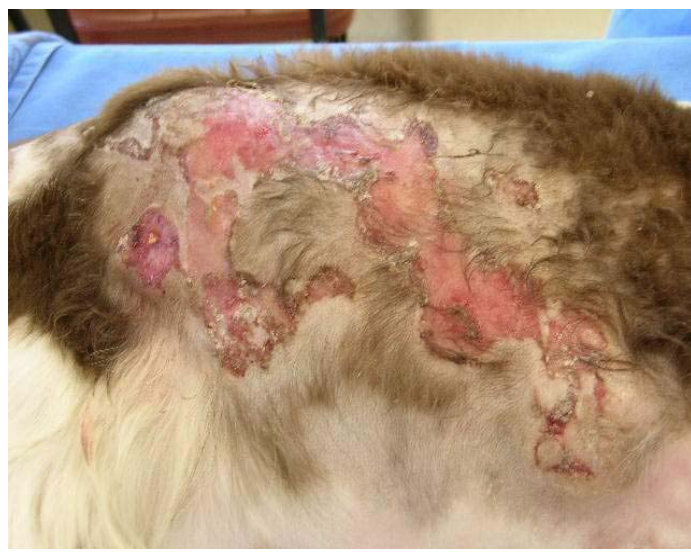

$\mathrm{D}$

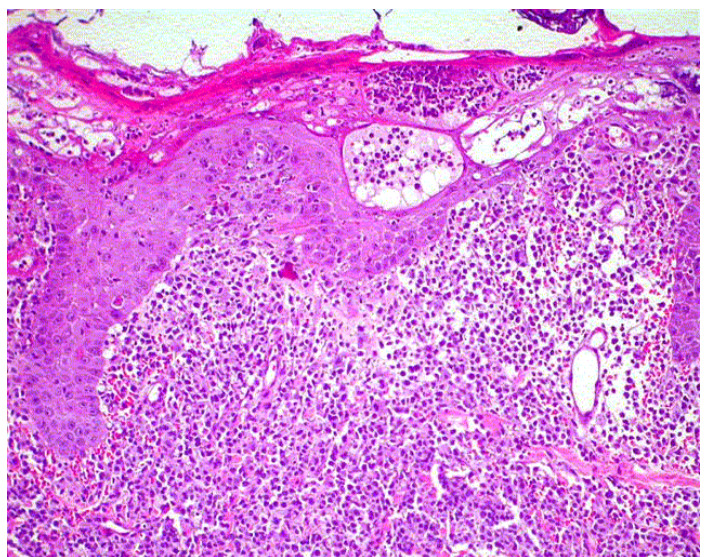

Figura 3. Infiltrado de linfócitos neoplásicos na derme e microabscessos de Pautrier na epiderme, em cadela com síndrome de Sézary. HE. 100x. 
A avaliação hematológica demonstrou anemia, neutrofilia e linfocitose caracterizada por linfócitos atípicos com núcleo hipercromático e aspecto cerebriforme. A avaliação citológica da medula óssea evidenciou relação mielóide:eritróide diminuída pelo aumento de precursores eritróides. Além disso, foi observada a presença de células da população linfóide com aspecto atípico associada a índice mitótico elevado, conferindo o diagnóstico de síndrome de Sézary. Devido à ausência de resposta ao tratamento quimioterápico e à rápida deterioração do quadro geral, o animal foi submetido à eutanásia.

A manifestação clínica inicial observada, neste trabalho, foi semelhante à relatada na micose fungóide (Morrison, 1998; Kasakov et al., 2004): com a progressão da doença, foram evidenciados sinais compatíveis com a síndrome de Sézary.

Em cães e seres humanos, a síndrome de Sézary é uma forma de linfoma epiteliotrópico de ocorrência rara, evolução subaguda e fatal (Thrall et al., 1984; Ghernati et al.,1999). Na avaliação imunoistoquímica, observa-se a expressão de CD3 (linfoma de células T) (Fournel-Fleury et al., 2002), e na citometria de fluxo a expansão clonal em sangue periférico de CD4 e CLA (antígenos de linfócitos cutâneos) (Wojdylo et al., 2005).

Em seres humanos, diferentes modalidades terapêuticas são utilizadas no tratamento da síndrome de Sézary, incluindo radioterapia, fotoforese, quimioterapia e imunoterapia (Anadolu et al.,2005). Em cães o tratamento dos linfomas cutâneos freqüentemente é considerado frustrante. Os retinóides sintéticos, como a isotretinoina e o etretinato ou a quimioterapia com 1-asparaginase, lomustina e dacarbazina podem promover remissão parcial em alguns casos (Morrison, 1998), entretanto as remissões e tempo de sobrevida são curtos, sendo a mortalidade relacionada a hipercalcemia, hipertermia maligna, septicemia e síndrome inflamatória sistêmica (Anadolu et al., 2005).

Palavras-chave: cão, oncologia, linfoma epiteliotrópico

\begin{abstract}
The present report describes a case of Sezary syndrome in a canine with lymphadenomegaly, generalized erithroderma, intense pruritus and disseminated cutaneous nodules and plaques. Biopsy samples were taken from cutaneous nodules and plaques and were diagnosed epitheliotropic $T$ cell cutaneous lymphoma by histology and immunohistochemical stain. Bone marrow cytology confirms leukemia. Diagnosis of Sezary syndrome was achieved through clinical, hematological, citopathological, histopathological and immunohistochemical findings. The patient was treated with Madison-Wisconsin chemotherapy protocol, but died after two mouths of treatment.
\end{abstract}

Keywords: dog, oncology, epitheliotropic lymphoma

\section{REFERÊNCIAS BIBLIOGRÁFICAS}

ANADOLU, R.Y.; BIRAL,A.; SANLI, H. et al. Mycosis fungoides and sezary syndrome: therapeutic approach and outcome in 113 patients. Int. J. Dermatol., v.44, p.559-565, 2005 .

FOSTER, A.P.; EVANS, E.; KERLIN, R.L. et al. Cutaneous T-cell lymphoma with Sezary syndrome in a dog. Vet. Clin. Pathol., v.26, p.188-192, 1997.

FOURNEL-FLEURY, C.; PONCE, F.; FELMAN, P. et al. Canine T-cell lymphomas: a morphological, immunological and clinical study of 46 new cases. Vet. Pathol., v.39, p.92$109,2002$.

GHERNATI, I.; AUGER, C.; CHABANNE, L. et al. Characterization of a canine long-term T-cell line established from a dog with sezary syndrome and producing retroviral particles. Leukemia, v.13, p.1281-1290, 1999.

MORRISON, W.B. Lymphosarcoma. In: MORRISON, W.B. (Ed). Cancer in dogs and cats, Philadelphia: Lippincott Williams \& Wilkins, 1998. p. 688-691.

RUSSEL-JONES, R. Diagnosing erythrodermic cutaneous Tcell lymphoma. Br. J. Dermatol., v.153, p.1-5, 2005.

THRALL, M.A.; MACY, D.W.; SNYDER, S.P. et al. Cutaneous lymphosarcoma and leukemia in a dog resembling sézary syndrome in man. Vet. Pathol., v.21, p.182-186, 1984.

WOJDYLO, M.; WENZEL, J.; GAFFAL, E. et al. Absence of CD26 expression on skin-homing CLA+CD4+ T lymphocytes in peripheral blood is a highly sensitive marker for early diagnosis and therapeutic monitoring of patients with sezary syndrome. Clin. Exp. Dermatol., v.30, p.702-706, 2005 . 